\title{
Neuroepithelial transforming gene 1 functions as a potential prognostic marker for patients with non-small cell lung cancer
}

\author{
LI FANG $^{1}$, JIALIANG ZHU ${ }^{1}$, YUCHAO MA ${ }^{1}$, CAO HONG $^{1}$, SHENG XIAO $^{2}$ and LONGYU JIN ${ }^{1}$ \\ Departments of ${ }^{1}$ Cardiothoracic Surgery and ${ }^{2}$ Pathology, The Third Xiangya Hospital, \\ Central South University, Changsha, Hunan 410013, P.R. China
}

Received November 29, 2014; Accepted August 14, 2015

DOI: $10.3892 / \mathrm{mmr} .2015 .4385$

\begin{abstract}
Non-small cell lung cancer (NSCLC) is the most common histological cancer sub-type worldwide. Neuroepithelial transforming gene 1 (Net-1), a Ras homolog family member A-specific guanine nucleotide exchange factor, has been shown to be upregulated in several human cancer types. However, the clinical significance of Net-1 expression in NSCLC has remained elusive. The present study assessed Net-1 mRNA and protein levels by reverse-transcription quantitative polymerase chain reaction and western blot analysis of 64 cases of NSCLC as well as their adjacent normal tissues. Furthermore, Net-1 protein expression in tumor tissues derived from clinically annotated NSCLC cases at stages I-III was detected by immunohistochemical staining. The results showed that Net-1 mRNA and protein levels in NSCLC tissues were significantly elevated compared with those in their corresponding non-tumor tissues. In addition, Net-1 expression was strongly associated with the patients' pathological characteristics, including clinical stage, lymph node metastasis, distant metastasis and differentiation degree $(\mathrm{P}<0.05)$. In conclusion, the results of the present study suggested that Net-1 expression has a significant role in the tumorigenesis of distinct histotypes and sub-types of NSCLC, and may therefore be utilized as a biomarker as well as an important therapeutic target in NSCLC.
\end{abstract}

Correspondence to: Professor Longyu Jin, Department of Cardiothoracic Surgery, The Third Xiangya Hospital, Central South University, 138 Tongzipo Road, Yuelu, Changsha, Hunan 410013, P.R. China

E-mail: limcs51@gmail.com

Abbreviations: Net-1, neuroepithelial transforming gene 1; NSCLC, non-small cell lung cancer

Key words: neuroepithelial transforming gene 1, non-small cell lung cancer, reverse transcription quantitative polymerase chain reaction, western blot, immunohistochemical staining

\section{Introduction}

Lung cancer is the major cause of cancer-associated mortality worldwide (1). Non-small cell lung cancer (NSCLC), which accounts for $\sim 85-90 \%$ of patients with lung cancer, comprises three sub-types according to their histological characteristics: Adenocarcinoma, squamous cell carcinoma and large cell carcinoma (2,3). Despite recent advances in treatments of NSCLC, they have only yielded modest improvements in NSCLC patient outcomes, with the overall five-year survival rate remaining at $15 \%$ (4). Therefore, it is required to discover novel prognostic biomarkers as well as therapeutic targets for NSCLC. Neuroepithelial transforming gene 1 (Net-1) is a 54-kDa oncoprotein (5), which has also been recognized as a Ras homolog family member A (RhoA) guanine nucleotide exchange factor (GEF) (6), and which was initially identified in a neuroepithelioma cell line (5). Net-1 is a member of seven transmembrane four superfamily with two distinct isoforms (Net-1 and Net-1A) and has a crucial role in cell signal transduction, proliferation, migration and invasion; it is also indicative of a poor prognosis of cancer patients (7-10). Overexpression of Net-1 has been documented in a variety of human cancer types, including hepatocellular carcinoma, breast cancer, oesophageal adenocarcinoma, skin squamous cell carcinoma and gastric adenocarcinoma $(8,11-14)$. Silencing of Net-1 by small interfering RNAs (siRNAs) was shown to inhibit cancer cell motility, proliferation and extracellular matrix invasion (8-10). A growing number of studies have suggested that there may be cross-talk between the Net-1 and transforming growth factor $\beta$ signaling pathways in actin cytoskeletal re-organization (15-17). However, to the best of our knowledge, a comprehensive profiling of Net-1 expression and function in advanced NSCLC has not been performed.

The present study assessed the expression of Net-1 in NSCLC as well as normal adjacent lung tissues and performed correlation analyses with various clinicopathological characteristics in order to explore the p utilization of Net-1 as a potential target for the development of therapeutic agents as well as a novel tissue biomarker for human lung cancer.

\section{Materials and methods}

Clinical tissue samples. A total of 64 patients (16 women, 48 men) with NSCLC, who underwent radical surgical resection 
at the Department of Thoracic and Cardiovascular Surgery (The Third Xiangya Hospital, Central South University, Changsha, China) from April 2009 to October 2009, were enrolled in the present study. According to the criteria of the World Health Organization (2004) (18), the 64 cases were divided into 29 squamous cell carcinomas, 32 adenocarcinomas and 3 large-cell carcinoma. All tumors were staged on the basis of the tumor-nodes-metastasis (TNM) pathologic classification of the International Association for the Study of Lung Cancer (19). Primary tumor tissues and their corresponding adjacent normal tissues $(5 \mathrm{~cm}$ from the margin of the tumor) obtained from each surgical specimen were used for reverse-transcription quantitative polymerase chain reaction (RT-qPCR), western blot and immunohistochemical analyses. The protocol of the present study was approved by the Local Ethics committee of the Third Xiangya Hospital, Central South University. All patients provided written, informed consent, with separate written, informed consent obtained for the optional provision of tumour material for biomarker analyses, and from one patient for use of lung tissues.

RNA extraction and RT-qPCR. RT-qPCR was performed as described previously (20). Total RNA was extracted from tissue specimens using TRIzol reagent (Invitrogen Life Technologies, Inc., Carlsbad, CA, USA) according to the manufacturer's instructions. RNA yield and purity were assayed using a SmartSpec Plus Spectrophotometer (BioRad Laboratories, Inc., Hercules, CA, USA), comparing the A230/260 and A260/A280 ratios. First-strand cDNA synthesis (cDNA synthesis kit; Fermentas, Burlington, ON, Canada) was performed using random hexamers on $1 \mu \mathrm{g}$ of total RNA. The amplification was performed in a total volume of $20 \mu \mathrm{l}$ containing SYBR Premix Ex Taq (Tli RNaseH Plus; cat no. DRR820S; Clontech Laboratories, Inc., Mountainview, CA, USA). The qPCR protocol was as follows: Initial denaturation, $95^{\circ} \mathrm{C}$ for $1 \mathrm{~min}$; primer-extension was performed in 40 cycles, each cycle consisted of $95^{\circ} \mathrm{C}$ for $30 \mathrm{sec}, 60^{\circ} \mathrm{C}$ for $20 \mathrm{sec}, 72^{\circ} \mathrm{C}$ for $20 \mathrm{sec}$ and final extension at $72{ }^{\circ} \mathrm{C}$ for $10 \mathrm{~min}$. The qPCR results were quantified using a double standard curve. qPCR was performed using the following primer sets: Net-1 forward, 5'-CTCTCCAGCCCAGTCTCACA-3' and reverse, 5'-CCC TCACACTCTTCGTGCAG-3') and $\beta$-actin forward, 5'-GTC CACCTTCCAGCAGATGT-3' and reverse, 5'-CTGTCACCT TCACCGTTCCA-3' (Sangon Biotech Co,. Ltd., Shanghai, China). Amplifications was performed in 40 cycles. Each cycle consisted of $30 \mathrm{sec}$ at $95^{\circ} \mathrm{C}, 5 \mathrm{sec}$ at $95^{\circ} \mathrm{C}$ and $20 \mathrm{sec}$ at $60^{\circ} \mathrm{C}$. mRNA levels were determined using the comparative CT method. The expression levels of each gene were normalized to those of $\beta$-actin, which served as an endogenous internal control.

Protein isolation and western blot analysis. Tumor tissues were extracted using radioimmunoprecipitation assay (RIPA) lysis buffer (Thermo Fisher Scientific, Waltham, MA, USA). The protein concentration in all samples was determined using a Bicinchoninic Acid Protein Assay kit (cat no. 23227; Thermo Fisher Scientific). Protein lysates were subjected to $10 \%$ SDS-PAGE followed by transfer onto a polyvinylidene difluoride membrane (EMD Millipore, Billerica, MA, USA). After blocking with $5 \%$ non-fat dry milk in Tris-buffered saline containing Tween 20 (Sigma-Aldrich, St. Louis, MO, USA) for $60 \mathrm{~min}$, the membrane was incubated with the primary antibody overnight at $4^{\circ} \mathrm{C}$. The following primary antibodies were used: Rabbit anti-human NET-1 (cat no. 2500682; 1:1,000; Sigma-Aldrich) and $\beta$-actin (cat no. sc47778; 1:2,000; Santa Cruz Biotechnology, Inc., Dallas, TX, USA). Following three subsequent washing steps, the membranes were incubated with peroxidase-conjugated polyclonal rabbit anti-human secondary antibody (cat no. P0212; 1:2,000; DakoCytomation, Glotstrup, Denmark) at room temperature for $2 \mathrm{~h}$. The blots were detected using an enhanced chemiluminescence detection kit (Bio-Rad Laboratories, Inc.) according to the manufacturer's instructions. The immunoreactive bands were scanned using an LAS-4000 imaging system (Fuji, Tokyo, Japan) to detect protein expression levels. The results were analyzed using Image Pro Plus 6.0 software (Media Cybernetics, Rockville, $\mathrm{MD}, \mathrm{USA}$ ) to determine the relative band density ratio.

Immunohistochemical staining. Immunohistochemistry (IHC) was performed on formalin-fixed paraffin-embedded (FFPE) histological sections. FFPE specimens were sectioned at $4 \mu \mathrm{m}$ onto charged slides and heated for $30 \mathrm{~min}$ at $60^{\circ} \mathrm{C}$. Slides were de-paraffinized in three sequential baths of xylene for $3 \mathrm{~min}$ each, re-hydrated using a graded series of ethanol for $5 \mathrm{~min}$ and then washed for $5 \mathrm{~min}$ in distilled water. Following de-paraffinization, antigen retrieval was performed using citrate buffer $(0.1 \mathrm{~mol} / \mathrm{l}, \mathrm{pH} 6.0)$ in a pressure cooker for $90 \mathrm{~min}$. Slides were then cooled in water and washed in phosphate-buffered saline (PBS). Intrinsic peroxidase activity was blocked using $3 \% \mathrm{H}_{2} \mathrm{O}_{2}$ (Beyotime Institute of Biotechnology, Haimen, China) in methanol at room temperature for $15 \mathrm{~min}$. The slides were then rinsed three times each with PBS. To block non-specific antibody binding, the sections were incubated with $3 \%$ fetal bovine serum for $60 \mathrm{~min}$ at $37^{\circ} \mathrm{C}$ in a humidified chamber. The slides were washed with PBS and then incubated with rabbit anti-human NET-1 polyclonal antibody (cat no. SAB2500682; 1:1,000; Sigma-Aldrich) overnight at $4^{\circ} \mathrm{C}$. Following incubation, sections were washed with PBS and subsequently incubated with goat anti-rabbit monoclonal secondary antibody (cat. no. M080825; 1:100; Zhong Shan Golden Bridge Biotechnology Co., Ltd) at $37^{\circ} \mathrm{C}$ for $30 \mathrm{~min}$. Finally, specimens were stained with 3,3'-diaminobenzidine (Shanghai Mingrui Biological Technology Co., Ltd., Shanghai, China) and counterstained with hematoxylin (Beyotime Institute of Biotechnology) at $37^{\circ} \mathrm{C}$ for $30 \mathrm{~min}$. All incubations were performed at room temperature. An experienced pathologist evaluated and scored the immunohistochemical expression using a light microscope (magnification, x200). Net-1 expression was quantified using customary scoring for intensity and the percentage reactivity. Intensity of staining was graded as follows: 0, without stain; 1, straw yellow; 2, brown; 3, dark brown. The extent of staining was evaluated as follows: $0, \leq 5 \%$ positive cells; $1,6-25 \%$ positive cells; 2 , $26-50 \%$ positive cells; $3,51-75 \%$ positive cells; and $4,>75 \%$ positive cells. The final immunoreactivity score was obtained by multiplying the intensity and reactivity scores: IRS $\leq 2$ was defined as negative, 2-5 point was defined as weak positive (+); $5-9$ points was defined as moderate positive $(++)$ and $>9$ points was defined as strong positive $(+++)(21)$. 
Table I. Association between Net-1 protein expression in tumors and various clinicopathological factors of 64 patients with non-small cell lung cancer.

\begin{tabular}{|c|c|c|c|}
\hline Characteristic & Cases (n) & Net-1 protein expression & P-value \\
\hline Gender & & & 0.184 \\
\hline Male & 15 & $2.86 \pm 1.54$ & \\
\hline Female & 5 & $1.87 \pm 0.55$ & \\
\hline Age, years & & & 0.322 \\
\hline$>60$ & 8 & $3.01 \pm 1.90$ & \\
\hline$\leq 60$ & 12 & $2.35 \pm 0.98$ & \\
\hline Smoking history & & & 0.184 \\
\hline Smoker & 15 & $2.86 \pm 1.54$ & \\
\hline Non-smoker & 5 & $1.87 \pm 0.55$ & \\
\hline Tumor size & & & 0.790 \\
\hline$>3 \mathrm{~cm}$ & 15 & $2.56 \pm 1.42$ & \\
\hline$\leq 3 \mathrm{~cm}$ & 5 & $2.76 \pm 1.56$ & \\
\hline Histological type & & & 0.351 \\
\hline Scc & 15 & $2.44 \pm 1.16$ & \\
\hline Ac & 5 & $3.14 \pm 2.09$ & \\
\hline Tumor differentiation & & & 0.031 \\
\hline Moderate & 15 & $2.44 \pm 1.11$ & \\
\hline Poor & 5 & $3.29 \pm 2.40$ & \\
\hline TNM stage & & & 0.042 \\
\hline I & 5 & $2.10 \pm 1.31$ & \\
\hline II & 13 & $2.62 \pm 1.52$ & \\
\hline III & 2 & $2.80 \pm 1.41$ & \\
\hline Lymph node metastasis & & & 0.011 \\
\hline Present & 8 & $2.73 \pm 1.11$ & \\
\hline Absent & 12 & $2.44 \pm 1.86$ & \\
\hline
\end{tabular}

Scc, squamous carcinoma; Ac, adenocarcinoma; Net-1, neuroepithelial transforming gene 1; TNM, tumor-nodes-metastasis.

Statistical analysis. Values are expressed as the mean \pm standard error of the mean. Differences among the groups were determined by two-way analysis of variance followed by Tukey's post-hoc test. Comparisons between the two independent groups were performed using an unpaired Student's $t$-test. All analyses were performed using SPSS 17.0 for Windows (SPSS, Inc., Chicago, IL, USA). P $<0.05$ was considered to indicate a statistically significant difference.

\section{Results}

Net-1 is overexpressed in NSCLC. To investigate Net-1 expression in NSCLC, the present study quantitatively examined the mRNA expression levels of Net- 1 in primary NSCLC tissues and their corresponding adjacent non-cancerous tissues. As shown in Fig. 1,RT-qPCR analysis revealed that NSCLC tissues exhibited higher levels of Net-1 expression compared to those in the corresponding adjacent non-cancerous tissues $(\mathrm{P}<0.05)$. In order to assess whether the differences in Net-1 expression between tumor and non-neoplastic samples are also present at the protein level, the present study subsequently examined the expression of Net-1 protein in lung cancers as well as in their

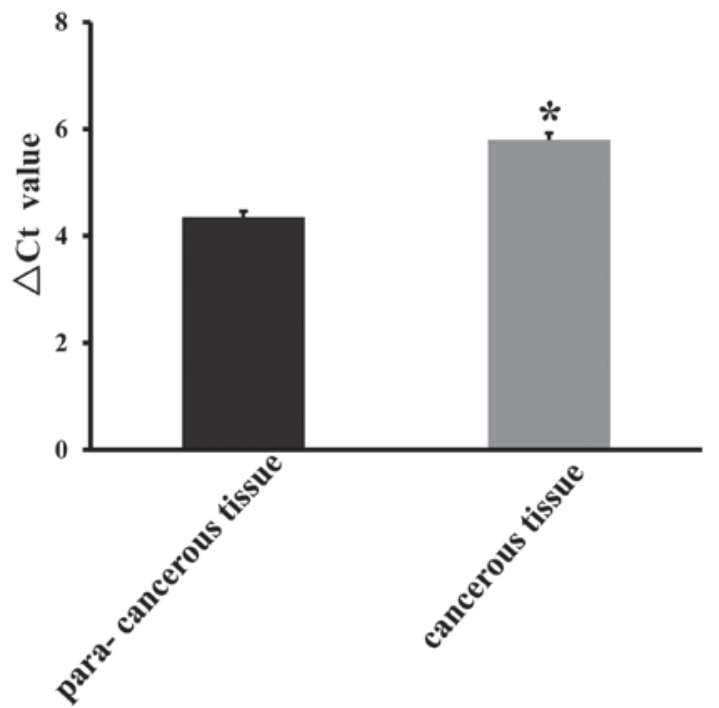

Figure 1. Comparison of Net-1 mRNA expression levels in cancerous and para-carcinoma tissues. Net-1 expression in non-small cell lung cancer and normal lung tissues of 64 patients were determined using reverse-transcription quantitative polymerase chain reaction analysis. Values are expressed as the mean \pm standard error of the mean. ${ }^{*} \mathrm{P}<0.05$, vs. para-carcinoma tissues. $\mathrm{Ct}$, cycle threshold; Net-1, neuroepithelial transforming gene 1 . 
Table II. Correlation between Net-1 and clinicopathological characteristics of 64 patients with non-small cell lung cancer.

\begin{tabular}{|c|c|c|c|c|c|c|}
\hline \multirow[b]{2}{*}{ Characteristic } & \multirow[b]{2}{*}{ Cases (n) } & \multicolumn{4}{|c|}{ Patients with Net-1 expression score, n (\%) } & \multirow[b]{2}{*}{ P-value } \\
\hline & & - & + & ++ & +++ & \\
\hline Gender & & & & & & 0.141 \\
\hline Male & 15 & $0(0.0 \%)$ & $7(46.7 \%)$ & $3(20.0 \%)$ & $5(33.3 \%)$ & \\
\hline Female & 5 & $2(40.0 \%)$ & $1(20.0 \%)$ & $1(20.0 \%)$ & $1(20.0 \%)$ & \\
\hline Age, years & & & & & & 0.920 \\
\hline$>60$ & 8 & $1(12.5 \%)$ & $3(37.5 \%)$ & $1(12.5 \%)$ & $3(37.5 \%)$ & \\
\hline$\leq 60$ & 12 & $1(8.3 \%)$ & $5(41.7 \%)$ & $3(25.0 \%)$ & $3(25.0 \%)$ & \\
\hline Smoking history & & & & & & 0.141 \\
\hline Smoker & 15 & $0(0.0 \%)$ & $7(46.7 \%)$ & $3(20.0 \%)$ & $5(33.3 \%)$ & \\
\hline Non-smoker & 5 & $2(40.0 \%)$ & $1(20.0 \%)$ & $1(20.0 \%)$ & $1(20.0 \%)$ & \\
\hline Tumor size & & & & & & 0.892 \\
\hline$>3 \mathrm{~cm}$ & 15 & $2(13.3 \%)$ & $5(33.3 \%)$ & $3(20.0 \%)$ & $5(33.3 \%)$ & \\
\hline$\leq 3 \mathrm{~cm}$ & 5 & $0(0.0 \%)$ & $3(60.0 \%)$ & $1(20.0 \%)$ & $1(20.0 \%)$ & \\
\hline Histological type & & & & & & 0.237 \\
\hline $\mathrm{Scc}$ & 15 & $0(0.0 \%)$ & $8(53.3 \%)$ & $2(13.3 \%)$ & $5(33.3 \%)$ & \\
\hline $\mathrm{Ac}$ & 5 & $2(40.0 \%)$ & $0(0.0 \%)$ & $2(40.0 \%)$ & $1(20.0 \%)$ & \\
\hline Tumor differentiation & & & & & & 0.021 \\
\hline Moderate & 15 & $2(12.5 \%)$ & $8(50.0 \%)$ & $3(18.8 \%)$ & $3(18.8 \%)$ & \\
\hline Poor & 5 & $0(0.0 \%)$ & $0(0.0 \%)$ & $1(25.0 \%)$ & $3(75.0 \%)$ & \\
\hline TNM stage & & & & & & 0.023 \\
\hline $\mathrm{I}$ & 5 & $0(0.0 \%)$ & $4(80.0 \%)$ & $1(20.0 \%)$ & $0(0.0 \%)$ & \\
\hline II & 13 & $2(15.4 \%)$ & $4(30.8 \%)$ & $2(15.4 \%)$ & $5(38.5 \%)$ & \\
\hline III & 2 & $0(0.0 \%)$ & $0(0.0 \%)$ & $1(50.0 \%)$ & $1(50.0 \%)$ & \\
\hline Lymph node metastasis & & & & & & 0.005 \\
\hline Present & 8 & $1(12.5 \%)$ & $0(0.0 \%)$ & $2(25.0 \%)$ & $5(62.5 \%)$ & \\
\hline Absent & 12 & $1(8.3 \%)$ & $8(66.7 \%)$ & $2(16.7 \%)$ & $1(8.3 \%)$ & \\
\hline
\end{tabular}

Scc, squamous carcinoma; Ac, adenocarcinoma; Net-1, neuroepithelial transforming gene 1; TNM, tumor-nodes-metastasis.

matched normal adjacent tissues using western blot analysis. The expression levels of Net-1 protein in NSCLC tissues were significantly higher than those in non-cancerous tissues, which was in accordance with the mRNA expression levels of Net-1 detected by real-time RT-PCR. Representative blots are shown in Fig. 2A and B. The finding that Net-1 is overexpressed in NSCLC specimens compared with non-cancerous tissues suggests the significance of Net-1 as a potential prognostic biomarker.

Net-1 overexpression is associated with poor clinical outcome of NSCLC. To further elucidate the biological and clinicopathological significance of Net-1 in NSCLC, 64 paraffin-embedded NSCLC tissue specimens were examined by IHC staining. The association of Net-1 expression and clinicopathological parameters is illustrated in Table I. As shown in Fig. 3A-D, positive immunostaining for Net-1 was mostly observed in the tumor cells of NSCLC tissues. In addition, Net-1 expression was significantly upregulated in primary NSCLC tissues compared to that in their corresponding adjacent non-cancerous tissues. Semi-quantitative IHC analysis indicated that Net-1 staining in primary NSCLC was higher than that in adjacent non-cancerous tissues. The Net-1 staining intensity gradually increased in accordance with the clinical stages from stages I-III $(\mathrm{P}<0.005)$ (Fig. 3D). Furthermore, statistical analysis showed that high Net-1 expression was strongly associated with the differentiation degree $(\mathrm{P}=0.021)$, clinical stage $(\mathrm{P}=0.023)$, lymph node metastasis $(\mathrm{P}=0.005)$ and distant metastasis $(\mathrm{P}<0.005)$ of patients with NSCLC, and this association is further summarized in Table II. However, no statistically significant association between high Net-1 expression and other clinicopathological variables, including gender, age, smoking history, tumor size or histological type, was identified. These results supported the hypothesis that Net-1 is involved in the regulation of the invasive ability of NSCLC.

\section{Discussion}

The present study reported for the first time, to the best of our knowledge, that Net-1 mRNA expression was upregulated in NSCLC tissues compared to that in their corresponding adja- 
A
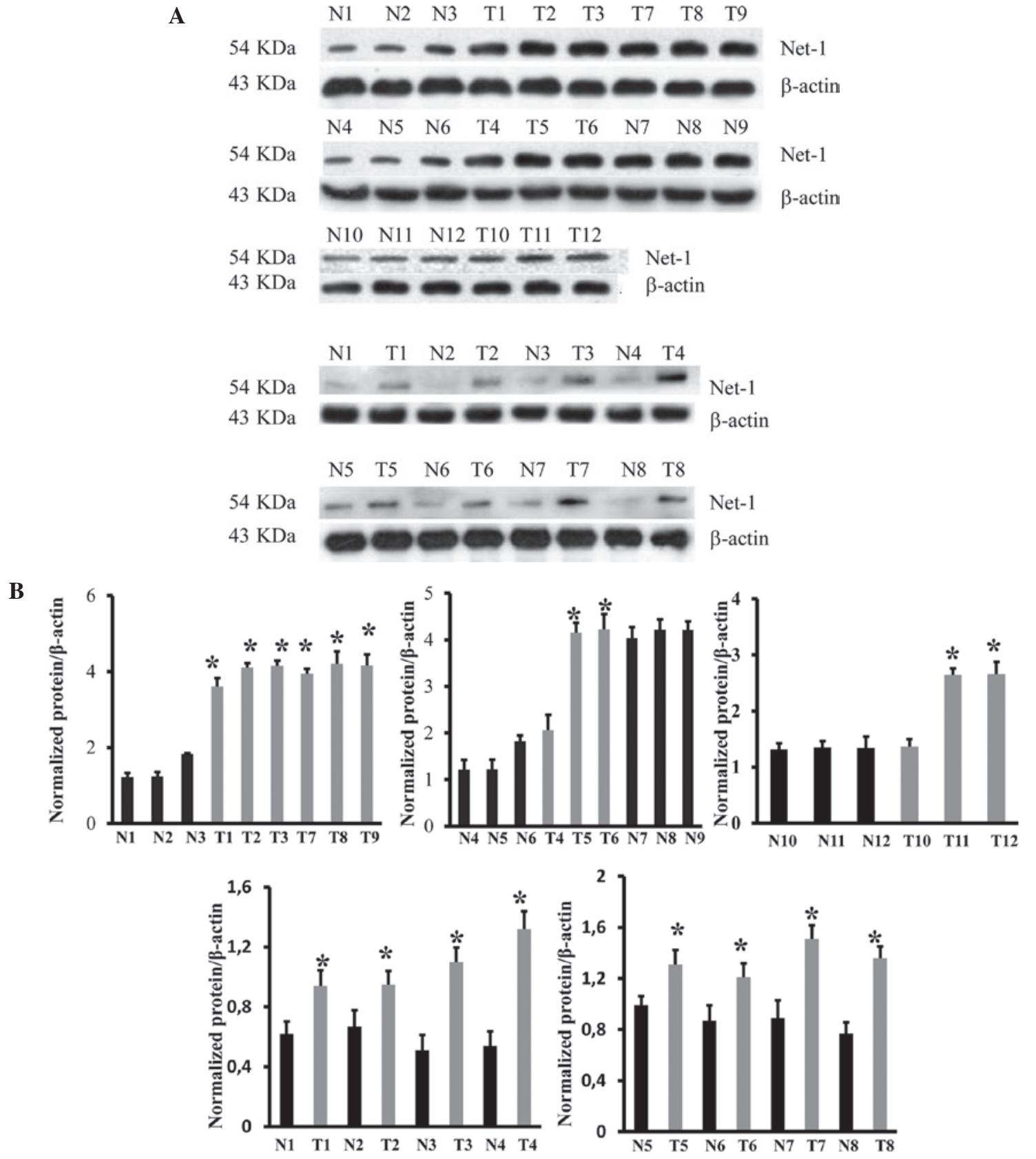

Figure 2. (A) Western blot analysis indicated that Net-1 is overexpressed in NSCLC tissues compared to that in the corresponding adjacent non-cancerous tissues from the same patient. (B) Quantitative results of western blot analysis. * P<0.05, vs. N group. N, normal lung tissue, T, NSCLC specimens; NSCLC, non-small cell lung cancer; Net-1, neuroepithelial transforming gene 1.

cent non-cancerous tissues. High-level Net-1 protein expression was also observed in 12 NSCLC patients, suggesting that elevated expression of Net-1 may contribute to the development of NSCLC. Clinical staging of cancer is based on the TNM classification, which is used to determine the clinical outcome and prognosis (22). By analyzing the correlation between clinicopathological variables of patients and Net-1 protein expression, the present study found that high Net-1 expression in NSCLC was significantly correlated with the differentiation degree, clinical stage, lymph node metastasis and distant metastasis. Multivariate analysis showed that Net-1 may be used as an independent prognostic biomarker for patients with NSCLC.

Previous studies supports the notion that Net-1 is frequently overexpressed in various cancer types, including hepatocellular carcinoma, gastric cancer, gliomas, cervical carcinomas and breast cancer (10,23-26). Using IHC staining, Lahiff et al (14) found that Net-1 expression is markedly increased in invasive and metastatic adenocarcinoma of the oesophagogastric junction. Murray et al (9) demonstrated that the migration and invasion of AGS gastric cancer cells are inhibited by Net-1-specific small interfering RNA. In addition, the study found that knockdown of Net-1 resulted in the formation of round cells and a loss of definition in the actin cytoskeleton (9). Zhang et al (13) further elucidated the role of NET-1 as a vital regulator of invasion and metastasis in the tumor, and reported that overexpression of Net-1 increases the likelihood of aggressive features in patients with squamous cell carcinoma of the skin As a GEF specific for RhoA, Net-1 is able to mediate 


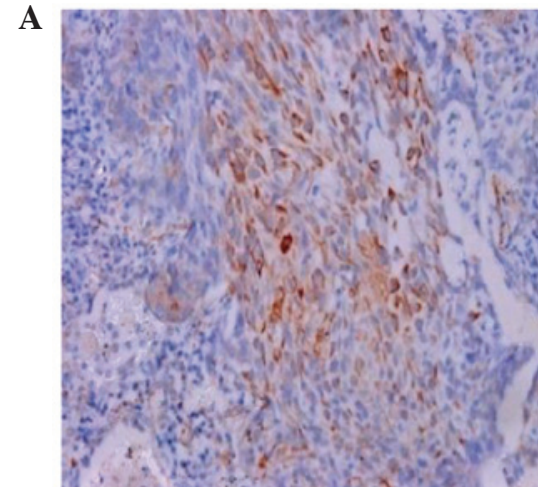

\section{Squamous carcinoma}

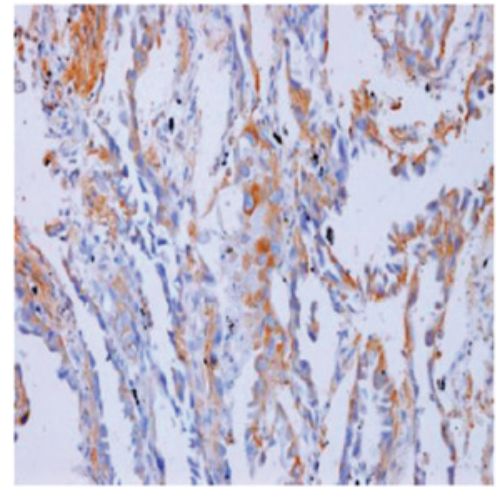

Adenocarcinoma

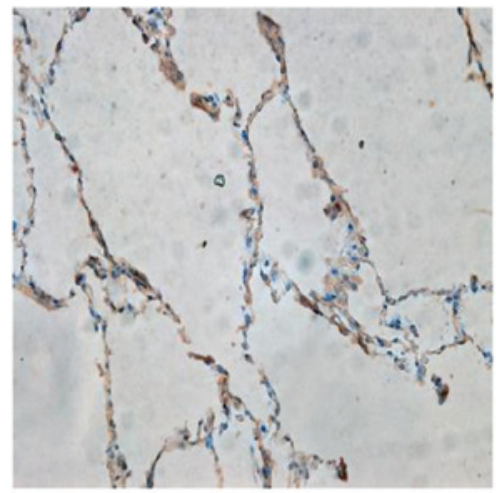

Normal lung tissues

B

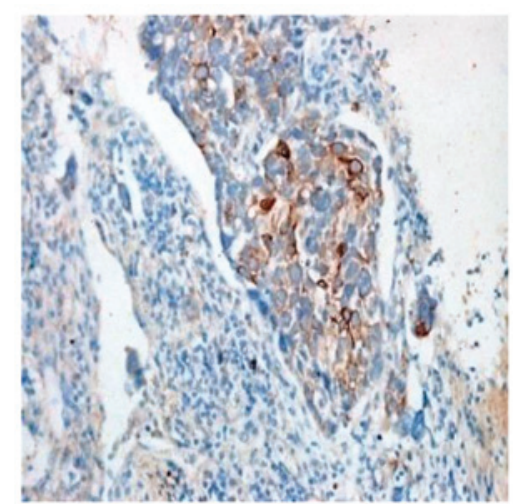

Lymph node metastasis

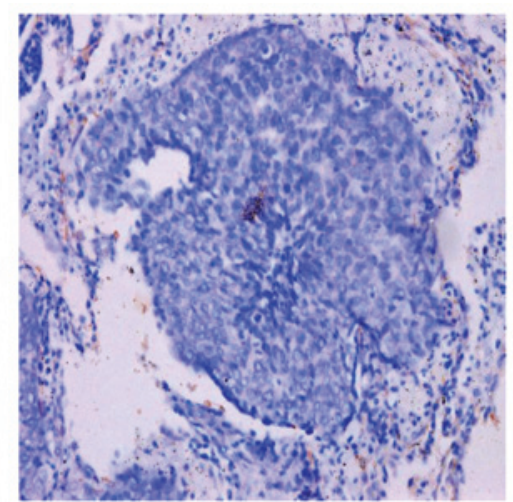

C

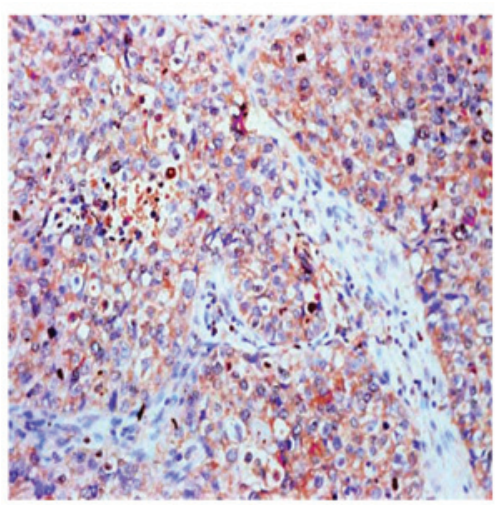

poor differentiation

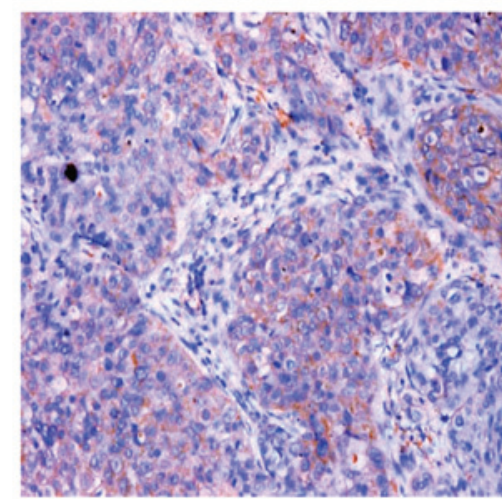

good differentiation

D

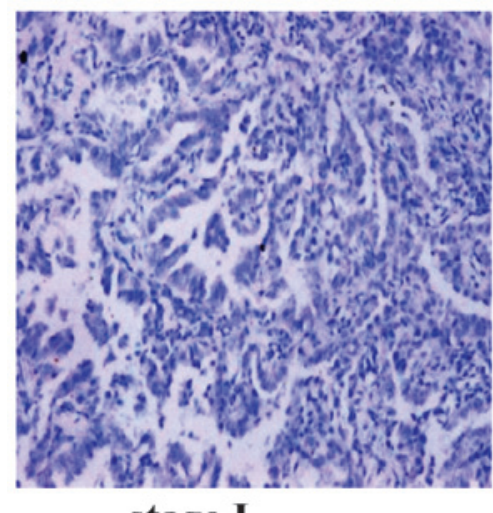

stage I

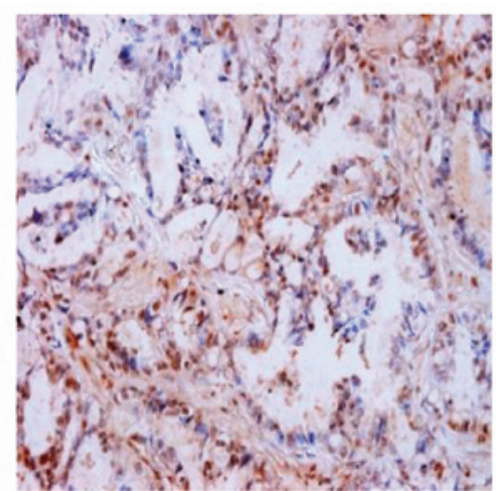

stage II

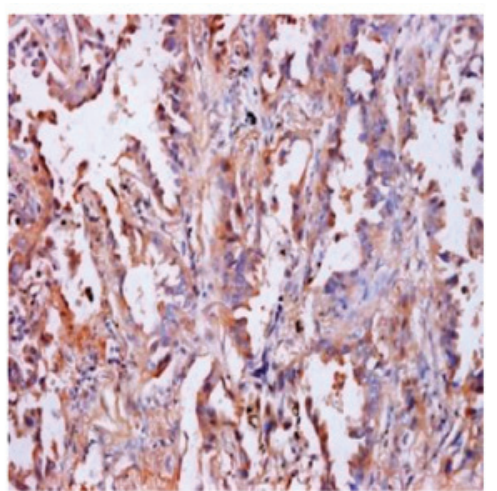

stage III

Figure 3. Expression of Net-1 in NSCLC tissues. (A) Representative immunohistochemical images showing high Net-1 expression in NSCLC samples (B) Expression of Net-1 is strongly associated with lymph node metastasis in lung cancer tissue. (C) Expression of Net-1 is associated with the degree of differentiation of NSCLC. (D) Expression of Net-1 in various clinical stages of NSCLC. Proteins expression of Net-1 exhibited positive staining in tumour tissues and negative staining in normal lung tissues (magnification, x200). NSCLC, non-small cell lung cancer; Net-1, neuroepithelial transforming gene 1. 
RhoA activation. Activated Rho proteins are able to stimulate signaling in multiple pathways by binding to target proteins, modulating their activities and thereby regulating a range of biological processes, including cell proliferation, apoptosis, differentiation and cytoskeletal reorganization, signal transduction (6). Recently, Zhang et al (13) further elucidated the role of NET-1 as a vital regulator of invasion and metastasis in the tumor and reported that overexpression of Net-1 greatly increases the likelihood of the aggressive feature in human skin squamous cell carcinoma patients. These studies suggested that Net-1 has vital roles in the metastasis of malignant tumors. However, the association between Net-1 and NSCLC has remained elusive. In order to investigate the involvement of Net-1 in NSCLC, the present study detected its mRNA and protein expression in 64 paired NSCLC tissues by RT-qPCR and western blot analysis. Furthermore, Net-1 protein expression in NSCLC tumor specimens was assessed by IHC and subjected to a correlation analysis with regard to clinicopathological features. The results showed that Net-1 expression was significantly elevated in tumor tissues compared to that in their corresponding non-tumor tissues. In addition, the results of the present study indicated that upregulation of Net-1 may be an important event in the development and progression of NSCLC. The levels of Net-1 expression were strongly correlated with the differentiation degree, clinical stage and lymph node metastasis in the NSCLC patients assessed in the present study. Based on these results, Net-1 is likely to be a tumor-promoting molecule and may contribute to the pathogenesis and progression of NSCLC. The results of the present study indicated that Net-1 expression is an independent prognostic factor for the outcome of patients with advanced NSCLC. The findings of the present study not only suggested that Net-1 may be a promising prognostic biomarker, but also implied a possible link between the biological function of Net-1 and the pathogenesis of NSCLC. Net-1 may therefore be an important therapeutic target for NSCLC treatment. However, further study is required in order to elucidate the molecular mechanism of the involvement of Net-1 in the progression of NSCLC.

The present study had certain limitations. The comprehensive mechanisms of Net-1 in NSCLC cells still remains to be investigated. Furthermore, patient data regarding cancer recurrence and mortality were not available for the cohort of the present study. Furthermore, the present study was performed in a retrospective manner on a relatively small number of cases. Thus, the findings of the present study require confirmation by future studies using a larger patient cohort and appropriate design.

In conclusion, to the best of our knowledge, the present study was the first to demonstrate that Net-1 is overexpressed in NSCLC and correlated with the differentiation degree, clinical stage and lymph node metastasis as well as unfavorable prognosis of NSCLC patients. The results of the present study provided novel insight into the function of Net-1 in the development and progression of NSCLC and reported a potential therapeutic target for this malignancy.

\section{Acknowledgements}

The present study was supported by the National Natural Scientific Foundation (grant no. 81472774) and the Research
Programme of the Science and Technology Department of Hunan Province (grant nos. 2012FJ4076 and 2012TT2011).

\section{References}

1. Jemal A, Bray F, Center MM, Ferlay J, Ward E and Forman D: Global cancer statistics. CA Cancer J Clin 61: 69-90, 2011.

2. Herbst RS, Heymach JV and Lippman SM: Lung cancer. N Engl J Med 359: 1367-1380, 2008.

3. Gong H, Han S, Yao H, Zhao H and Wang Y: AP4 predicts poor prognosis in nonsmall cell lung cancer. Mol Med Rep 10: 336-340, 2014.

4. Reck M: What future opportunities may immuno-oncology provide for improving the treatment of patients with lung cancer? Ann Oncol 23 (Suppl 8): viii28-viii34, 2012.

5. Chan AM, Takai S, Yamada K and Miki T: Isolation of a novel oncogene, NET-1, from neuroepithelioma cells by expression cDNA cloning. Oncogene 12: 1259-1266, 1996.

6. Rossman KL, Der CJ and Sondek J: GEF means go: Turning on RHO GTPases with guanine nucleotide-exchange factors. Nat Rev Mol Cell Biol 6: 167-180, 2005.

7. Yauch RL and Hemler ME: Specific interactions among transmembrane 4 superfamily (TM4SF) proteins and phosphoinositide 4-kinase. Biochem J 351: 629-637, 2000.

8. Leyden J, Murray D, Moss A, Arumuguma M, Doyle E, McEntee G, O'Keane C, Doran P and MacMathuna P: Net-1 and Myeov: Computationally identified mediators of gastric cancer. $\mathrm{Br}$ J Cancer 94: 1204-1212, 2006

9. Murray D,Horgan G, Macmathuna P and Doran P:NET-1-mediated RhoA activation facilitates lysophosphatidic acid-induced cell migration and invasion in gastric cancer. Br J Cancer 99: 1322-1329, 2008

10. Ecimovic P, Murray D, Doran P, McDonald J, Lambert DG and Buggy DJ: Direct effect of morphine on breast cancer cell function in vitro: Role of the NET-1 gene. Br J Anaesth 107: 916-923, 2011.

11. Wang GL, Chen L, Wei YZ, Zhou JM, Wu YY, Zhang YX, Qin J and Zhu YY: The effect of NET-1 on the proliferation, migration and endocy tosis of the SMMC-7721 HCC cell line. Oncol Rep 27: 1944-1952, 2012

12. Abba MC, Hu Y, Sun H, Drake JA, Gaddis S, Baggerly K, Sahin A and Aldaz CM: Gene expression signature of estrogen receptor alpha status in breast cancer. BMC Genomics 6: 37, 2005.

13. Zhang J, Wang J, Chen L, Wang G, Qin J, Xu Y and Li X: Expression and function of NET-1 in human skin squamous cell carcinoma. Arch Dermatol Res 306: 385-397, 2014.

14. Lahiff C, Schilling C, Cathcart MC, Mulligan N, Doran P, Muldoon C, Murray D, Pidgeon GP, Reynolds JV and Macmathuna P: Prognostic significance of neuroepithelial transforming gene 1 in adenocarcinoma of the oesophagogastric junction. Br J Surg 101: 55-62, 2014.

15. Papadimitriou E, Vasilaki E, Vorvis C, Iliopoulos D, Moustakas A, Kardassis D and Stournaras C: Differential regulation of the two RhoA-specific GEF isoforms Net-1/Net-1A by TGF- $\beta$ and miR-24: Role in epithelial- to -mesenchymal transition. Oncogene 31: 2862-2875, 2012.

16. Lee J, Moon HJ, Lee JM and Joo CK: Smad3 regulates Rho signaling via NET1 in the transforming growth factor-betainduced epithelial-mesenchymal transition of human retinal pigment epithelial cells. J Biol Chem 285: 26618-26627, 2010.

17. Shen X, Li J, Hu PP, Waddell D, Zhang J and Wang XF: The activity of guanine exchange factor NET1 is essential for transforming growth factor-beta-mediated stress fiber formation. J Biol Chem 276: 15362-15368, 2001.

18. Travis WD, Garg K, Franklin WA, Wistuba II, Sabloff B, Noguchi M, Kakinuma R, Zakowski M, Ginsberg M, Padera R, et al: Bronchioloalveolar carcinoma and lung adenocarcinoma: the clinical importance and research relevance of the 2004 World Health Organization pathologic criteria. J Thorac Oncol 9: S13-9 (2006).

19. Travis WD, Brambilla E, Noguchi M, et al.: International Association for the Study of Lung Cancer/American Thoracic Society/European Respiratory Society: international multidisciplinary classification of lung adenocarcinoma: executive summary. Proc Am Thorac Soc 8: 381-385, 2011.

20. Jin L, Li C, Xu Y, Wang L, Liu J, Wang D, Hong C, Jiang Z, Ma Y, Chen Q and Yu F: Epigallocatechin gallate promotes p53 accumulation and activity via the inhibition of MDM2-mediated p53 ubiquitination in human lung cancer cells. Oncol Rep 29: 1983-1990, 2013. 
21. Birner P, Oberhuber G, Stani J, Reithofer C, Samonigg H, Hausmaninger H, Kubista E, Kwasny W, Kandioler-Eckersberger D, Gnant M, et al: Evaluation of the United States Food and Drug Administration-approved scoring and test system of HER-2 protein expression in breast cancer. Clin Cancer Res 7: 1669-1675, 2001.

22. Mirsadraee S, Oswal D, Alizadeh Y, Caulo A and van Beek E Jr: The 7th lung cancer TNM classification and staging system: Review of the changes and implications. World J Radiol 4: 128-134, 2012.

23. Bennett G, Sadlier D, Doran PP, Macmathuna P and Murray DW: A functional and transcriptomic analysis of NET-1 bioactivity in gastric cancer. BMC Cancer 11: 50, 2011.
24. Shen SQ, Li K, Zhu N and Nakao A: Expression and clinical significance of NET-1 and PCNA in hepatocellular carcinoma. Med Oncol 25: 341-345, 2008.

25. Tu Y, Lu J, Fu J, Cao Y, Fu G, Kang R, Tian X and Wang B: Over-expression of neuroepithelial-transforming protein 1 confers poor prognosis of patients with gliomas. Jpn J Clin Oncol 40: 388-394, 2010.

26. Wollscheid V, Kühne-Heid R, Stein I, Jansen L, Köllner S, Schneider A and Dürst M: Identification of a new proliferation-associated protein NET-1/C4.8 characteristic for a subset of high-grade cervical intraepithelial neoplasia and cervical carcinomas. Int J Cancer 99: 771-775, 2002. 